\title{
Sustainability transformations as shifts in worldviews: a dynamic view of complementarity issues
}

\author{
Cyrille Rigolot $^{1}$
}

Key Words: adaptation; quantum theory; social change; sustainability; transformation; worldview

\section{COMMENTARY}

In their stimulating paper, Alrøe and Noe (2016) propose a generalization of the complementarity principle from quantum theory to sustainability assessment, defined as overall assessment produced by "bringing together different perspectives that pertain to sustainability." A wealth of approaches and tools have been developed in the last decades (Schader et al. 2014), but two key issues remain: (1) the integration problem, i.e., the fact that different tools produce different assessments (Schader et al. 2014); and (2) the implementation problem, i.e., the barrier between sustainability assessment and transformation (Triste et al. 2014). Taken in the radical sense of Niels Bohr, the complementary principle means that "two observations of an object, such as the determination and momentum of an elementary particle, exclude each other in such a way that prevents getting the full picture of the object, so we are left with complementary phenomena that cannot be combined" (Alrøe and Noe 2016). From their long experience with assessments of food systems, Alrøe and Noe (2016) have identified two relevant forms of complementarity:

- Observer stance complementarity corresponds to the fundamental methodological form of complementarity, as defined by quantum mechanics. In short, "the conditions for defining the observed system as it is (without interaction) precludes the conditions necessary for observing it (with interactions)." Elaborating on this, Alrøe and Noe (2016) distinguish two modes of science: detached ("describing the world as it is and producing general knowledge") and involved ("focusing on enabling action and change in concrete context"). These two modes of science correspond notably to two sustainability assessment tools (complex and expert-based vs. simpler and participatory; Marchand et al. 2014). Another form of observer stance complementarity lies in the assessment position, whether it is "from without" or "from within." For example, in farm sustainability assessment, Schader et al. (2014) distinguish a farm perspective (from within) and a societal perspective (from without). Taking it one step further, Alrøe and Noe (2016) extend the "within-without" principle by considering multiple actors in the food chain.

- In value complementarity, "the mutual exclusion of two observations of the same object stems from different values that determine what observations are relevant or desirable." The focus here is on the normative conditions of observation. Alrøe and Noe (2016) give three examples of value complementarity: naturalness vs. care to value animal welfare, authentic vs. rich nature to value nature quality, and three perspectives to value growth and sustainable development (growth without borders, growth within limits, and growth and ecological injustice).

Because of value complementarity, Alrøe and Noe (2016) claim, the integration problem cannot be overcome, only better handled. To do so, the authors point out the fundamental limits of indexation (i.e., integrating different kinds of assessments, typically into a number), and the need to distinguish between complementarity and dilemmas. The complementarity principle also provides an explanation for the implementation problem because assessment and transformation are based on two incompatible modes of science (detached and involved observer stance). Therefore, according to the authors, "the implementation problem cannot be resolved by developing still more advanced and complex methods, if these approaches employ a detached observer stance that is directed by the norms of science."

In this comment, I propose another explanation of the implementation problem, based on a dynamic view of complementary issues and the concept of worldview. In their paper, Alrøe and Noe (2016) suggest seeing value complementarity "as a sort of path dependency: When one path has been chosen out of two possible, the other path is no longer available or possible." In my understanding, they do not consider (at least explicitly) the possibility that value complementarities might shift at the scale of individuals during the transformation process, and what the implications could be for sustainability assessment. Consequently, they use the terms "transitions" and "sustainability transformations" interchangeably. However, according to Beddoe et al. (2009), in a comprehensive approach of transformation, a "regime shift cannot occur without changing worldviews, institutions and technologies together, as an integrated system." On this basis, some authors suggest making a clear distinction between transitions and sustainability transformations, the later of which implies a shift in worldview (O'Brien and Sygna 2013). Further, O'Brien (2012) develops the concept of deliberate transformations, which involves "the intentional breaking down of specific resilience of the old system ([including value path dependencies]) and building resilience in the new system." In the next paragraphs, I first show that a given worldview is associated with specific values and correlated observer stance complementarities (by definition). Then, I argue more precisely that different ideal-typical worldviews identified in the literature are associated with Alrøe and Noe's (2016) specific examples of complementarity. I also give some literature references developing the idea that sustainability transformations require a shift in worldview. Finally, I develop the implications of 
a dynamic view of complementarity issues for sustainability assessments and the implementation problem from my own experience in farm sustainability assessment and transformations.

Worldview has been defined as "a structuring system of meaning, informing how humans interpret and co-create reality" (Hedlundde Witt 2012). According to Hedlund-de Witt (2012), a worldview can be described following five dimensions: ontological (basic assumptions on the nature of reality), epistemological (modes of knowledge), axiological (specific values), anthropological (the nature of human beings and their position in the universe), and societal (how to organize society). This worldview concept is essential to understand how different kinds of complementarities are related: Specific values are correlated with specific modes of knowledge (observer stance), as well as with specific ontological, anthropological, and societal assumptions. The correlation of different value complementarities is well identified by Alrøe and Noe (2016): "the specific issues of value complementarity are not independent of the overall complementarity between different meaning of sustainability." They also suggest some links between value complementarity and observer stance complementarity: "Secondarily, there may be methodological constrains involved in value complementarity, but the primary cause is a difference in value." Here, I argue that observer stance complementarity can also reciprocally involve specific values, ontological assumptions, and so on. Therefore, deep changes involving several complementarities and dimensions might happen: This corresponds to a "shift in worldview." A growing literature demonstrates that such shifts in worldview are possible at the scale of individuals and societies (Schlitz et al. 2010).

On the basis of social, historical, and psychological studies, several typologies of worldviews have been proposed (van Egmond et de Vries 2011). Particularly, three major types of worldview seem to be consistent across multiple typologies: traditional, modern, and postmodern (O'Brien and Hochachka 2010). Particularly, in Alrøe and Noe's (2016) terms, the modern worldview is typically characterized by a detached observer stance (objective science) and a correlated vision of nature quality promoting authenticity (associated with a naturalist ontology, where man and nature are seen as separated; Descola 2005). The postmodern worldview is typically characterized by involved observer stance (participative sciences) and a correlated vision of nature quality promoting richness (man and nature seen as integrated). Concise but comprehensive descriptions of worldviews are given in O'Brien and Hochachka (2010) and Hedlund-de Witt (2012). Some authors also agree on a fourth emerging major worldview integrating science and spirituality, which is often called integral (van Egmond and de Vries 2011). Many authors have argued that the modern worldview is responsible for the current ecological crisis, and that sustainable pathways require developing alternative worldviews (Bonneuil and Fressoz 2016, Latour 2017). In my interpretation, this is in line with the vision of Folke and Gunderson (2002) for the journal Ecology and Society, which assumes that seeing "humanity and nature as co-evolving systems" (which goes past a modern worldview where both are seen as separated) (...) will "enhance our capacity to actively adapt to change without eroding resilience or creating vulnerability." This is also consistent with an evolutionary approach to worldview, as proposed in integral theory (Wilber 2000) and spiral dynamics (Beck and Cowan
2014). In this evolutionary approach, the four major worldview types can be seen as successive stages of individual and collective development. No worldview type can be considered as intrinsically better than another, but some worldviews are more and less adapted to the context (Wilber 2000). The modern worldview, which has been very useful in human history, is not adapted anymore to be the dominant worldview globally in the context of the ecological crisis, although it can still be useful (Wilber 2000). The relationship between worldviews and sustainable lifestyle is discussed by Hedlund-de Witt (2012).

Considering sustainability transformations as shifts in worldviews has important implications for the development of new strategies and the role of sustainability assessments. Particularly, criteria, methods, and assumptions used in current sustainability assessment are virtually meaningless for the same actor in a new transformed system because of complementarity issues with emerging worldviews. From my own experience in farm sustainability assessment and transformations, this a key explanation for the implementation problem, together with observer stance complementarity, as I will illustrate with two examples. From my experience in conventional French pig production systems, sustainability assessment tools such as life cycle assessment are not mutually excluding, but are in fact very synergic with some deep technical transitions such as the development of large slurry anaerobic digestion facilities (Rigolot et al. 2009, Espagnol et al. 2012). As long as they do not imply a shift in (modern) worldview, important technical transitions can still be significantly supported by "more advanced and complex methods for sustainability assessment," despite observer stance complementarity. Conversely, when studying the conversion of French livestock farmers to organic farming, we clearly identified an implementation problem (Huet et al. 2018). Indeed, even in places where assessments show that organic conversion would be obviously economically profitable for farmers, organic agriculture is far from having grown as much as the demand for organic products (Dedieu et al. 2017). In this case, the implementation problem can be explained by the shift in worldview, or "transformational change," involved in the conversion to organic farming (Sutherland et al. 2012, Huet et al. 2018). Particularly, during the conversion process, farmers' very conception of what is a "good farmer" can shift, as well as their own criteria to evaluate their farming practice (Sutherland et al. 2012, Huet et al. 2018). Alrøe and Noe (2016) are well aware of the specificities of "the organic understanding of sustainability," which is associated with specific (typically postmodern) value complementarities ("the pursuit of naturalness" for animal welfare and a "systemic conception of nature," valuing "rich but not untouched" nature). However, they do not consider the cases of farmers' conversion to organic farming, which are, in my opinion, particularly relevant for understanding the implementation problem. In such cases of sustainability transformation (implying a shift in worldview), sustainability assessments might be useless or counterproductive, unless they are associated with value-based approaches that aim at communicating and mediating sustainability values (Alrøe et al. 2017) or other multipleperspective approaches (Tengo et al. 2015). In my understanding, however, such approaches should be aimed not only at "coordinated and cooperative actions" (Alrøe et al. 2017), but, perhaps more importantly, at mutual transformations of 
stakeholders' own perspectives in the process (Rigolot 2017, Cayre et al. 2018).

As a conclusion, building on the major contribution of Alrøe and Noe (2016), my commentary introduces a dynamic view of complementary issues, with important implications for the development of sustainable strategies and the role of sustainability assessments. A first limit of this proposal is that ideal-typical worldviews might sound too simplistic. Particularly, Cayre et al. (2018) have shown that ideal-typical worldviews in fact coexist at both collective and individual scales, from a case study in French Protected Designation of Origin cheese mountain areas in agroecological transition. For example, a dairy farmer can take a modern perspective for grazing management and a postmodern perspective for mowing management. However, farmers also often have a dominant worldview, which is sufficient for an evolutionary framework to remain consistent (Cayre et al. 2018). The dynamic nature of complementarity issues can also be questioned. Particularly, "the notion that worldviews are part of individual or collective sequential evolutions undermines the reality that in complex systems all of these exist at the same time, and that individual alignment with a particular worldview is contingent on conditions, events, etc. at any given time" (anonymous reviewer). This remark is challenging, as it raises deep issues with regard to the very nature of reality, as well as the possibility of free will and "deliberate transformation" (O'Brien 2012). In my opinion, this opens to other kinds of generalization from quantum theory, such as Wendt's (2006) interpretation of social life. Considering consciousness as a "macroscopic quantum phenomenon" (by analogy) and human beings as "walking wave functions,"Wendt (2006) states, "The desires and belief which the rationalist model of man sees as causal behavior actually do not exist until behavior takes place - before that point, the Self is a superposition of multiple and mutually incompatible desires and beliefs." Following Barad (2007), Alrøe and Noe (2016) warrant against such generalizations of quantum physics by analogy, and prefer a rigorous approach "following the deep philosophical implications of Bohr's thinking." However, as proposed by O'Brien (2016), both approaches might be synergic to provide a strong methodological, metaphorical, and meaningful basis for recognizing and promoting people as the solution for sustainable transformations.

Responses to this article can be read online at: http://www.ecologyandsociety.org/issues/responses. php/10101

\section{Acknowledgments:}

Thanks to an anonymous reviewer for very useful and stimulating comments on a previous version of this paper. This paper has also benefited from ideas developped as part of the French government IDEX-ISITE initiative 16-IDEX-0001 (CAP 20-25).

\section{LITERATURE CITED}

Alrøe, H. F., and E. Noe. 2016. Sustainability assessment and complementarity. Ecology and Society 21(1):30. http://dx.doi. org/10.5751/ES-08220-210130
Alrøe, H. F., M. Sautier, K. Legun, J. Whitehead, E. Noe, H. Moller, and J. Manhire. 2017. Performance versus values in sustainability transformation of food systems. Sustainability 9 (3):332. http://dx.doi.org/10.3390/su9030332

Barad, K. 2007. Meeting the universe halfway: quantum physics and the entanglement of matter and meaning. Duke University Press, Durham, North Carolina, USA. http://dx.doi. org/10.1215/9780822388128

Beck, D. E., and C. C. Cowan. 2014. Spiral dynamics: mastering values, leadership, and change. Wiley, Hoboken, New Jersey, USA.

Beddoe, R., R. Costanza, J. Farley, E. Garza, J. Kent, I. Kubiszewski, L. Martinez, T. McCowen, K. Murphy, N. Myers, Z. Ogden, K. Stapleton, and J. Woodward. 2009. Overcoming systemic roadblocks to sustainability: the evolutionary redesign of worldviews, institutions, and technologies. Proceedings of the National Academy of Sciences 106(8):2483-2489. http://dx.doi. org/10.1073/pnas.0812570106

Bonneuil, C., and J.-B. Fressoz. 2016. The shock of the Anthropocene: the Earth, history and us. Verso, New York, New York, USA.

Cayre, P., A. Michaud, J.-P. Theau, and C. Rigolot. 2018. The coexistence of multiple worldviews in livestock farming drives agroecological transition. A case study in French Protected Designation of Origin (PDO) cheese mountain areas. Sustainability 10(4):1097. http://dx.doi.org/10.3390/su10041097

Dedieu, M.-S., A. Lorge, O. Louveau, and V. Marcus. 2017. Les exploitations en agriculture biologique: quelles performances économiques? Pages 35-44 in C. Demaison, L. Grivet, D. MauryDuprey, and S. Mayo-Simbler, editors. Les acteurs économiques et l'environnement - Edition 2017. Institut national de la statistique et des études économiques, Paris, France. [online] URL: https:// www.insee.fr/fr/statistiques/3280952

Descola, P. 2005. Par-delà nature et culture. Gallimard, Paris, France.

Espagnol, S., A. Rugani, C. Baratte, C. Roguet, M. Marcon, A. Tailleur, C. Rigolot, and J.-Y. Dourmad. 2012. Référentiel environnemental et socio-économique des systèmes d'élevage porcin conventionnels français: base pour le pilotage d'une amélioration environnementale. Journées de la Recherche Porcine en France 44:109-114. [online] URL: http://www.journeesrecherche-porcine.com/texte/2012/environnement/E2f.pdf

Folke, C., and L. Gunderson. 2002. A kaleidoscope of change. Conservation Ecology 6(1):19. http://dx.doi.org/10.5751/ES-00359-060119

Hedlund-de Witt, A. 2012. Exploring worldviews and their relationships to sustainable lifestyles: towards a new conceptual and methodological approach. Ecological Economics 84:74-83. http://dx.doi.org/10.1016/j.ecolecon.2012.09.009

Huet, S., C. Rigolot, Q. Xu, Y. De Cacqueray-Valmenier, and I. Boisdon. 2018. Toward modelling of transformational change processes in farm decision-making. Agricultural Sciences 9 (3):83261. http://dx.doi.org/10.4236/as.2018.93024

Latour, B. 2017. Où atterrir? Comment s'orienter en politique. La Découverte, Paris, France. 
Marchand, F., L. Debruyne, L. Triste, C. Gerrard, S. Padel, and L. Lauwers. 2014. Key characteristics for tool choice in indicatorbased sustainability assessment at farm level. Ecology and Society 19(3):46. http://dx.doi.org/10.5751/ES-06876-190346

O'Brien, K. 2012. Global environmental change II: from adaptation to deliberate transformation. Progress in Human Geography 36(5):667-676. http://dx.doi.org/10.1177/0309132511425767

O'Brien, K., and G. Hochachka. 2010. Integral adaptation to climate change. Journal of Integral Theory and Practice 5 (1):89-102.

O'Brien, K., and L. Sygna. 2013. Responding to climate change: the three spheres of transformation. Pages 16-23 in Proceedings of transformation in a changing climate. University of Oslo, Oslo, Norway.

O'Brien, K. L. 2016. Climate change and social transformations: Is it time for a quantum leap? Wiley Interdisciplinary Reviews: Climate Change 7(5):618-626. https://doi.org/10.1002/wcc.413

Rigolot, C. 2017. Une approche évolutive des "visions du monde" pour penser les transformations de l'agriculture. Cahiers Agricultures 26(3):36001. https://doi.org/10.1051/cagri/2017015

Rigolot, C., B. Méda, S. Espagnol, T. Trochet, and J.-Y. Dourmad. 2009. Analyses de cycle de vie (ACV) de 5 systèmes porcins avec différentes hypothèses de comptabilisation des impacts. Journées de la Recherche Porcine en France 41:281-282.

Schader, C., J. Grenz, M. S. Meier, and M. Stolze. 2014. Scope and precision of sustainability assessment approaches to food systems. Ecology and Society 19(3):42. http://dx.doi.org/10.5751/ ES-06866-190342

Schlitz, M. M., C. Vieten, and E. M. Miller. 2010. Worldview transformation and the development of social consciousness. Journal of Consciousness Studies 17(7-8):18-36.

Sutherland, L.-A., R. J. F. Burton, J. Ingram, K. Blackstock, B. Slee, and N. Gotts. 2012. Triggering change: towards a conceptualisation of major change processes in farm decisionmaking. Journal of Environmental Management 104:142-151. http://dx.doi.org/10.1016/j.jenvman.2012.03.013

Tengö, M., E. S. Brondizio, T. Elmqvist, P. Malmer, and M. Spierenburg. 2014. Connecting diverse knowledge systems for enhanced ecosystem governance: the multiple evidence base approach. Ambio 43:579-591. http://dx.doi.org/10.1007/ s13280-014-0501-3

Triste, L., F. Marchand, L. Debruyne, M. Meul, and L. Lauwers. 2014. Reflection on the development process of a sustainability assessment tool: learning from a Flemish case. Ecology and Society 19(3):47. http://dx.doi.org/10.5751/ES-06789-190347

van Egmond, N. D., and H. J. M. de Vries. 2011. Sustainability: the search for the integral worldview. Futures 43(8):853-867. http://dx.doi.org/10.1016/j.futures.2011.05.027

Wendt, A. 2006. Social theory as cartesian science: an autocritique from a quantum perspective. Pages 181-219 in S. Guzzini and A. Leander, editors. Constructivism and international relations: Alexander Wendt and his critics. Routledge, London, UK.
Wilber, K. 2000. Sex, ecology, spirituality: the spirit of evolution. Second edition. Shambhala, Boston, Massachusetts, USA. 